ORIGINAL ARTICLE

\title{
The Relationship Between Parents and Children In Influencing Adolescents' Sexual Behavior
}

\author{
SARWINANTI ${ }^{1}$, INESTY CHANDRA ${ }^{2}$ \\ ${ }^{1,2}$ Faculty of Health 'Aisyiyah University of Yogyakarta \\ Correspondent author to Sarwinanti email: sarwi.73@unisayogya.ac.id
}

\begin{abstract}
Background: The survey result of SDKI (Basic Survey of Indonesian Demography and Health) in 2012 on $K R R$ (Adolescents' reproductive health) shows that approximately $9.3 \%$ or 3.7 million adolescents have had sexual intercourse, while the result of SKRRI (Survey of Adolescents' Reproductive Health) shows that approximately $7 \%$ or 3 million adolescents have had sexual intercourse. One of the environmental factors on adolescents' reproductive behavior is the family factor. Adolescents who have had premarital sexual intercourse mostly come from broken homes, which has many conflicts and problems.

Aim: The study investigates the correlation between parents and children relationship and adolescents' sexual behavior at Bantul.

Method: The study used a cross-sectional approach and analytical correlation. The total sampling technique was used to draw 81 respondents as the samples. The data were analyzed using Chi-square statistical test.

Result: The chi-square statistical test result showed that 34 respondents had a good relationship with their parents (42), and 16 respondents had a lack of relationship with their parents. Forty-seven respondents (58\%) showed negative sexual behavior. P-value was $0.015(p<0,05)$, meaning a correlation between parents' close relationship and adolescents' sexual behavior at senior high school in Bantul.

Conclusion: There is a correlation between parents and children relationship and adolescents' sexual behavior at senior highs schools in Bantul. Adolescents and parents should be more open to each other in discussing their problems, especially their reproductive health because it is one of the ways to build a good relationship between parents and adolescents
\end{abstract}

Keywords: relationship, adolescents' sexual behavior, parents and children

\section{INTRODUCTION}

According to the data from $B K K B N$ in 2013, the number of adolescents aged $10-24$ years old reached 64 million or $27.6 \%$ of all Indonesian citizens. Adolescents' sexual behavior has become the world's problem. Adolescents' sexual behavior in Indonesia has also become a threat [1]. Based on SDKI in 2012, there was an increase of adolescents who have had premarital sexual intercourse at a national rate compared to the same source in 2007. Some adolescents' sexual behaviors show profound impacts such as guilty feelings, depression, anger, unintended pregnancy, reproductive organ disease, infectious diseases, and HIV/AIDS, as well as abortion [2]. According to the data from Study Centre for Sexuality (PSS) of PKBI DIY in 2015, in DIY, $62.1 \%$ of adolescents had ever hug their couple during dating, $60.5 \%$ of adolescents had ever held their couple's hand, $59.1 \%$ of adolescents had ever done french kiss, and $60 \%$ adolescents had ever had petting. Early marriage or underage marriage in Bantul increased in the last ten years. Mostly, it is because there is unintended pregnancy. Based on the Religious Affairs Office (KUA) data in Bantul in 2014, the number of marriage dispensation was 132 cases from 204 requests [3]. Recently, society still considers that sexuality is taboo to discuss. There are many differences of perception related to sex education as the strategy to decrease adolescents pregnancy. Appropriate parents' role will influence adolescents personality into a better one. Thus, parents need to be more open-minded about all issues and topics so that their children can be more independent, disciplined, and responsible [4]. The government's policy to prevent premarital sex in adolescents has been mentioned in Government regulation Number 61year of 2014 article 12 about adolescents' reproductive health service [5]. The previous study in senior high school in Bantul shows that according to an interview with ten students; $4 \mathrm{X}$ grade students, 3 XI grade students, and 3 XII grade students, seven students had a close relationship with their parents, while $100 \%$ of them have boy/girlfriend and $70 \%$ of them have ever hug and kissed their couple. Based on the data formerly mentioned, the researcher is interested in investigating the correlation between parents' relationship and adolescents' sexual behavior in senior high school at Bantul.

\section{METHOD}

The data collection technique in the research employed a questionnaire and checklist given to respondents. Total sampling was used to draw samples. The data were analyzed using the chi-square test.

\section{RESULTS AND DISCUSSION}

Based on Table 1, the research results showed that most respondents were female, namely 43 respondents (53.1\%). Besides, most respondents were 16 years old, as many as 35 respondents (43.2\%). According to Ross (2010), one's age can influence decision-making in other fields such as education, occupation, and maturity in thought and acts [6].

Based on table 2, it can be seen that most respondents had a good relationship with parents, namely 34 respondents (42\%). Besides, 31 respondents (38.2\%) had a moderate relationship with their parents, and 16 respondents had a poor relationship with their parents. 
Thus, parents had a very significant role in affecting sexual behavior in adolescents. The result is in line with Marchand (2013), who stated that environmental factors that firmly affect adolescents' sexual behavior are family. Adolescents who had premarital sexual intercourse mostly came from a broken home family with problems or divorced parents [7]. Moreover, Meschke (2002) states that a close relationship between parents and children must be started early to not look for safety outside the family environment [8]. Parents will know children's needs with a good relationship before they look for satisfaction outside the family environment. Many children are still unable to choose the proper way to actualize themselves, such as through drugs, premarital sex, etc. The research results showed that out of all respondents, $34.6 \%$ of the respondents stated that they had rarely told their problems about their parents. $52.6 \%$ of the respondents stated that sometimes their parents did not know their activity outside their house. This means that most respondents had a low level of trust in their parents. It also becomes the factor causing disharmony in the family because there was no openness between adolescents and their parents. This is in line with research by theory from Lefkowitz (2006), arguing that adolescents perceive that their parents do not have the capability in sexual topics, cannot be trusted, tend to judge, overprotective, and often do not respect privacy and adolescents' desire to be independent [9].

Based on table 3 , it can be seen that most respondents (47 respondents) had negative sexual behavior (58\%), and 34 respondents had positive sexual behavior $(42 \%)$. The result is in line with Riza's research (2016), stating that out of 118 respondents, 97 respondents $(80.2 \%)$ had negative sexual behavior. However, the result is not following research by Puspitadewi (2015), revealing that 109 respondents had low sexual behavior (94\%). Respondents who had moderate sexual behavior were four respondents $(3.4 \%)$, and respondents with high sexual behavior were three respondents (2.6\%).

Table 1. Frequency distribution of respondents' characteristics

\begin{tabular}{|l|l|l|}
\hline Characteristics & Frequency $(\mathrm{n})$ & Percentage $(\%)$ \\
\hline Sex & & \\
\hline Female & 43 & 53.1 \\
\hline Male & 38 & 46.9 \\
\hline Ages & & \\
\hline 15 years old & 12 & 14.8 \\
16 years old & 35 & 43.2 \\
17 years old & 34 & 42 \\
\hline
\end{tabular}

Table 2. Frequency of distribution parents' relationship with children in "X" senior high school in Bantul

\begin{tabular}{|l|l|l|}
\hline Parents' relationship & Frequency $(\mathrm{n})$ & Percentage (\%) \\
\hline Good & 34 & 42 \\
\hline Moderate & 31 & 38.3 \\
\hline Poor & 16 & 19.8 \\
\hline Total & 81 & 100 \\
\hline
\end{tabular}

Based on the research, $67 \%$ of respondents stated that they were always happy when their parents were worried about them, and $39 \%$ of respondents stated that sometimes when they discussed with their parents, their parents cared about their suggestions. Moreover, $70.2 \%$ of respondents stated that their parents never asked directly when they had difficulties. This proves that communication is vital in the family because communication is one of the closeness dimensions between parents and children. Thus, it can be concluded that the better communication is, the better children are. The result is similar to Feldman's theory (2000), which states that parents' harmonious grows optimum emotional life and personality development and vice versa [10].

Table 3. Frequency distribution of adolescents' sexual behavior in "X" senior high school in Bantul

\begin{tabular}{|l|l|l|}
\hline Sexual behavior & Frequency $(\mathrm{n})$ & Percentage(\%) \\
\hline Positive & 34 & 42 \\
\hline Negative & 47 & 58 \\
\hline Total & 81 & 100 \\
\hline
\end{tabular}

Based on the research result, it is also revealed that $58 \%$ of respondents had negative sexual behavior, and most of them were female. Namely, 27 respondents $(33.3 \%)$ and most of them were 17 years old, 23 respondents $(28.4 \%)$. The result of the research is in line with Starzyk et al. (2003) mentioning that the influencing factors of sexual behavior are personal factors (knowledge, attitude, gender, lifestyle, pride, and social activity) and demographic variables (age, sex, religious status, ethnic and marriage status) [11]. From the latest research result, $13.3 \%$ of respondents stated that they did not refuse to have a date. Besides, $8.6 \%$ stated that they wanted to have a boyfriend when they saw their friend had a boyfriend. This is expected behavior in adolescents in which they are interested in the opposite sex and is one of the sexual behavior forms. Sexual behavior is forced by sexual desire [12]. The forms can be various, starting from enjoyable feelings until dating, kissing, and sexual intercourse.

Based on the research, $3.6 \%$ of respondents admitted that they had ever read porn magazines, did not refuse to have lips kissing, and did not feel angry when their reproductive organs were touched. These are forms of sexual behavior, namely fantasizing, kissing, and touching each other. However, these should not be done by adolescents because they can lead them to premarital sexual behavior. The result follows Yule's research (2017), stating that the activity of sexual fantasy is usually followed by masturbation [13]. Sexual activity is an activity to fulfill sexual force or activity to gain intimate organs' pleasure through various behavior kinds. This research also reveals that $2.5 \%$ of respondents admitted that they had ever had an intimate activity with the opposite sex, and $67 \%$ were males.

Meanwhile, $3.6 \%$ of respondents had ever had read porn stories, and $35 \%$ were males and 17 years old. This proves that males tend to have negative sexual behavior. The result is in line with Buhi (2007), arguing that males have a higher risk of sexual behavior than female adolescents with a 4.41 times more significant risk of risky sexual behavior [14].

Besides, $2.5 \%$ of respondents admitted that they did not refuse lips kissing, and $13.4 \%$ of respondents did not refuse when they were asked to hug when riding a motorcycle. Both of them are included in kissing and hugging sexual behavior, which is considered typical nowadays. They believed that these did not have a severe impact. Negative sexual behavior emerges because of 
small things such as kissing and hugging. The research is also supported by the belief that premarital sexual behavior in adolescents emerges when they can adjust the situation to realize emotional force and thoughts about their sexual behavior or attitude towards sexual behavior. According to table 3, 34 respondents had a good relationship with their parents, and most of them, namely 19 respondents
(55.9\%), had positive sexual behavior. In comparison, 31 respondents had enough relationship with their parents, and most of them, namely 18 respondents (58.1\%), had negative sexual behavior. Out of 16 respondents who had a poor relationship with their parents had negative sexual behavior, namely 14 respondents (87.5\%).

Table 4. Correlation between parents' relationship and adolescents' sexual behavior

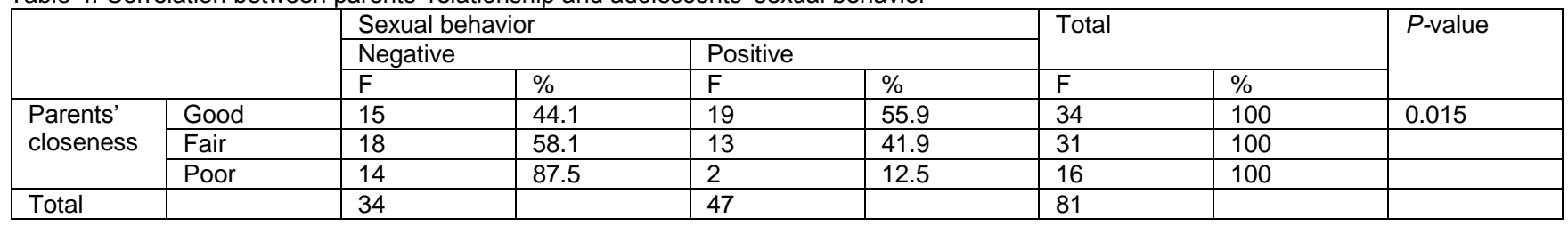

In Table 4 shows the $p$-value is 0.015 with a $5 \%$ significance level of $\alpha$ is 0.05 , meaning that $p$-value $(0.015)$ $<\alpha(0.05)$ and Ho is accepted. It can be concluded that there was a correlation between parents' relationship and adolescents' sexual behavior in " $X$ " senior high school in Bantul. This is caused by the poor relationship between parents and their children, which enlarged the risk of adolescents' sexual behavior due to disharmony in parents and children relationship and lack of trust from children to discuss personal matters with their parents. This caused children to find comfort outside the house and family, which leads them into negative activities such as premarital sex in adolescents.

The research result also revealed that adolescents who had a good relationship with their parents but had negative sexual behavior were as many as 15 respondents $(44.1 \%)$. The lack of trust caused them to discuss personal matters with parents, and parents tended to judge them because of their problems. Besides, they also considered that the behavior was expected among their friends to do similar behavior. A similar result is also stated by Jaccard (2000), which found that adolescents feel that their parents refuse to talk about premarital sex most of the time, so they look for other alternative information sources such as friends or mass media [15]. Jaccard (2000) also argued that adolescents badly need information related to sexual and reproductive matters [15]. They usually get inaccurate information from their friends, not from health officers, teachers, or parents. This is in line with Santelli (2004), stating that factors supporting adolescents to have sexual intercourse are their peers, which can be seen from adolescents' conformity. It forces an adolescent to have sexual intercourse [16]. Satcher (2001) states that group comfort can be when one adopts attitude or behavior from other people in his group or the pressure of reality or impression is given by the group [17]. If a peer's environment supports sexual behavior and group comfort is high, the adolescents can have premarital sexual intercourse.

School's role in giving knowledge about reproductive health influences sexual behavior in adolescents. Because adolescents feel uncomfortable discussing reproductive health topics with their parents, they tend to feel more comfortable talking with people outside their house, such as school. Thus, those who have a poor relationship with their parents can still have positive sexual behavior.

\section{CONCLUSION}

Based on the research result, most of the respondents had a good relationship with their parents, namely 34 respondents $(42 \%)$, and most of the respondents had negative sexual behavior, namely 47 respondents (58\%). There is a correlation between parents' relationship and adolescents sexual behavior in " $X$ " senior high school in Bantul withp a value $(0.015)<\alpha(0.05)$.

Adolescents should be more open to their parents, especially about their reproductive health. Parents should open more space to discuss adolescents' problems, especially related to reproductive health, and be more sensitive to their children's problems, especially during adolescence, because this helps them maintain a relationship between parents and children.

\section{REFERENCES}

1. A. Ediati, A. Z. Juniarto, E. Birnie, S. L. S. Drop, S. M. H. Faradz, and A. B. Dessens, "Gender Development in Indonesian Children problems especially Adults with Disorders of Sex Development," Arch. Sex. Behav., vol. 44, no. 5, pp. 1339-1361, Jul. 2015, doi: 10.1007/s10508-0150493-5.

2. D. B. Kirby, B. A. Laris, and L. A. Rolleri, "Sex and HIV Education Programs: Their Impact on Sexual Behaviors of Young People Throughout the World," J. Adolesc. Heal., vol. 40, no. 3, pp. 206-217, Mar. 2007, doi: 10.1016/j.jadohealth.2006.11.143.

3. N. Agtikasari, "The Correlation of Knowledge about Early Marriage And Students' Attitude Towards Early Marriage in SMA Negeri 2 Banguntapan 2015," J. Ners dan Kebidanan (Journal Ners Midwifery), vol. 4, no. 1, pp. 051-055, Apr. 2017, doi: 10.26699/jnk.v4i1.ART.p051-055.

4. M. V. Pop and A. S. Rusu, "The Role of Parents in Shaping and Improving the Sexual Health of Children - Lines of Developing Parental Sexuality Education Programmes," Procedia - Soc. Behav. Sci., vol. 209, pp. 395-401, Dec. 2015, doi: 10.1016/j.sbspro.2015.11.210.

5. Z. Shaluhiyah and N. J. Ford, "Sociocultural Context of Adolescent Pregnancy, Sexual Relationships in Indonesia, and Their Implications for Public Health Policies," in International Handbook of Adolescent Pregnancy, Boston, MA: Springer US, 2014, pp. 359-378.

6. L. L. Ross and A. M. Bowen, "Sexual Decision Making for the 'Better Than Average' College Student," J. Am. Coll. Heal., vol. 59, no. 3, pp. 211-216, Nov. 2010, doi: 10.1080/07448481.2010.502198.

7. E. Marchand and K. Smolkowski, "Forced Intercourse, 
Individual and Family Context, and Risky Sexual Behavior Among Adolescent Girls," J. Adolesc. Heal., vol. 52, no. 1, pp. 89-95, Jan. 2013, doi: 10.1016/j.jadohealth.2012.04.011

8. L. L. Meschke, S. Bartholomae, and S. R. Zentall, "Adolescent sexuality and parent-adolescent processes: promoting healthy teen choices," J. Adolesc. Heal., vol. 31, no. 6, pp. 264-279, Dec. 2002, doi: 10.1016/S1054139X(02)00499-8.

9. E. S. Lefkowitz and T. M. Stoppa, "Positive sexual communication and socialization in the parent-adolescent context," New Dir. Child Adolesc. Dev., vol. 2006, no. 112, pp. 39-55, 2006, doi: 10.1002/cd.161.

10. S. S. Feldman and D. A. Rosenthal, "The Effect of Communication Characteristics on Family Members' Perceptions of Parents as Sex Educators," J. Res. Adolesc., vol. 10, no. 2, pp. 119-150, Apr. 2000, doi: 10.1207/SJRA1002_1.

11. K. B. Starzyk and W. L. Marshall, "Childhood family and personological risk factors for sexual offending," Aggress. Violent Behav., vol. 8, no. 1, pp. 93-105, Jan. 2003, doi: 10.1016/S1359-1789(01)00053-2.

12. J. G. Pfaus et al., "Who, What, Where, When (and Maybe Even Why)? How the Experience of Sexual Reward Connects Sexual Desire, Preference, and Performance,"
Arch. Sex. Behav., vol. 41, no. 1, pp. 31-62, Feb. 2012, doi: 10.1007/s10508-012-9935-5.

13. M. A. Yule, L. A. Brotto, and B. B. Gorzalka, "Sexual Fantasy and Masturbation Among Asexual Individuals: An In-Depth Exploration," Arch. Sex. Behav., vol. 46, no. 1, pp. 311-328, Jan. 2017, doi: 10.1007/s10508-016-0870-8.

14. E. R. Buhi and P. Goodson, "Predictors of Adolescent Sexual Behavior and Intention: A Theory-Guided Systematic Review," J. Adolesc. Heal., vol. 40, no. 1, pp. 4-21, Jan. 2007, doi: 10.1016/j.jadohealth.2006.09.027.

15. J. Jaccard, P. J. Dittus, and V. V. Gordon, "Parent-Teen Communication about Premarital Sex," J. Adolesc. Res., vol. 15, no. 2, pp. 187-208, Mar. 2000, doi: $10.1177 / 0743558400152001$

16. J. S. Santelli, J. Kaiser, L. Hirsch, A. Radosh, L. Simkin, and S. Middlestadt, "Initiation of sexual intercourse among middle school adolescents: the influence of psychosocial factors," J. Adolesc. Heal., vol. 34, no. 3, pp. 200-208, Mar. 2004, doi: 10.1016/j.jadohealth.2003.06.004.

17. D. Satcher, "The Surgeon General's Call to Action to Promote Sexual Health and Responsible Sexual Behavior," Am. J. Heal. Educ., vol. 32, no. 6, pp. 356-368, Dec. 2001, doi: 10.1080/19325037.2001.10603498. 